\title{
Telemedicine units for COVID-19: An experience from Madhya Pradesh
}

\section{Sourabh Saxena ${ }^{1}$, Karishma Srivastava ${ }^{2}$, Roshni Dilbagi ${ }^{3}$, Ashish Saxena ${ }^{4}$}

${ }^{1}$ Technical Lead-Comprehensive Primary Health Care, WISH foundation, Bhopal, Madhya Pradesh; ${ }^{2}$ Head of Urban Health Program; WISH Foundation; New Delhi; ${ }^{3}$ NCD and capacity building specialist; WISH Foundation; Bhopal, Madhya Pradesh; ${ }^{4}$ Deputy Director-NCD; NHM MP; Bhopal, Madhya Pradesh

\begin{tabular}{|c|c|c|c|c|c|c|}
\hline$\underline{\text { Abstract }}$ & $\underline{\text { Introduction }}$ & Methodology & $\underline{\text { Conclusion }}$ & $\underline{\text { References }}$ & Citation & $\underline{\text { Tables / Figures }}$ \\
\hline \multicolumn{7}{|c|}{ Corresponding Author } \\
\hline \multicolumn{6}{|c|}{$\begin{array}{l}\text { Dr Sourabh Saxena, B-84, Palace Orchard, Kolar Road, Bhopal, Madhya Pradesh } \\
\text { E Mail ID: ssaxena@ wishfoundationindia.org }\end{array}$} & 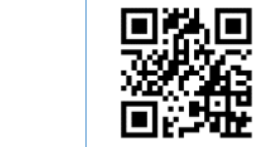 \\
\hline
\end{tabular}

\section{Citation}

Saxena S, Srivastava K, Dilbagi R, Saxena A. Telemedicine units for COVID-19: An experience from Madhya Pradesh. Indian J Comm Health. 2020;32(2-Special Issue):277-280.

Source of Funding: Nil Conflict of Interest: None declared

\section{Article Cycle}

Received: 11/04/2020; Revision: 14/04/2020; Accepted: 16/04/2020; Published: 20/04/2020

This work is licensed under a Creative Commons Attribution 4.0 International License.

On 31st December 2019, the World Health Organization (WHO) China Country Office was informed of cases of pneumonia of unknown aetiology detected in Wuhan City, Hubei Province of China.(1) The first cases of COVID-19 outside of China were identified on January 30 in India and it has spread to 210 countries in all world regions by 10 th April 2020, with more than 1.6 million confirmed and more than 0.1 million deaths worldwide.(2)

Disasters and pandemics pose exceptional challenges to providing health care. Though telemedicine will not solve them all, it is well suited for scenarios in which medical practitioners can evaluate and manage patients. Previous work has specifically described the potential for using telemedicine in disasters and public health emergencies, wherein Patients prioritize convenient and inexpensive care, whether in-person visits becomes the last option for meeting patient needs. $(3,4)$

Patients presenting for in-person care who screen positive for high-risk features should be isolated immediately to avert further contact with patients and health care workers.(5) A telemedicine consult can be conducted without exposing staff to viruses/infections in the times of such outbreaks. Telemedicine can prevent the transmission of infectious diseases thus reducing the risks to both health care workers and patients. Telemedicine not only avoids needless exposure of the potential infected individuals involved in the delivery of healthcare by screening the patients remotely but also provide speedy access to medical practitioners who may not be immediately available in person. In addition, it makes available extra working hands to provide medical care at the respective health institutions. Thus, health systems that have invested in telemedicine are well positioned to ensure that patients with COVID-19 or related issues, receive the care they need. India well-ordered 21-day lockdown on 24th March 2020, as a preemptive measure to fight COVID-19. Health facilities are predominantly used for managing COVID 19 patients now. While whole country is home quarantined, and in the backdrop of already stretched health system, it becomes quite farsighted to use telemedicine in the fight against COVID-19.

The Board of Governors, in supersession of Medical Council of India $(\mathrm{MCl})$, has adopted the "Telemedicine Practice Guidelines". These guidelines include both the overarching principles and a practical framework for implementation. While the overarching principles would be common to all future guidelines, the latter specifically tries to address the current need in the wake of COVID-19 outbreak.(6) The notification on 25th March 2020 clearly illustrates that Consultation through Telemedicine by the Registered Medical 
Practitioners (Medical Officers as per National Health Mission manpower context) under the Indian Medical Council Act, 1956 shall be permissible in accordance with the Telemedicine Practice Guidelines. The government of Madhya Pradesh in connect to new telemedicine guidelines by NITI Aayog has, with the support of WISH Foundation, set up a telemedicine unit at every district hospital which acts as a command centre. Identified home quarantined suspected persons are calling and/or receiving communications from their respective command centre at district hospital and are enquired about their health conditions. Appropriate health education and counselling are extended to the suspected home quarantined persons. In case the person exhibits symptoms of COVID-19, it is considered as an emergency and the information is communicated to Rapid Response Teams (RRT) or Mobile Medical Units (MMU), who will attend promptly to the patient without fail and if the symptoms are serious then the patient is referred to appropriate nearby health facility by connecting through ambulance services. Routine teleconsultations will be extended for those having other complaints. AlIMS Bhopal and other medical colleges are being synchronized with the role of extension of tertiary care services as required. The requirement with regard to infrastructure, logistics, human resource and other pertinent information related to telemedicine guidelines were estimated and districts were provided hand holding support telephonically and through communication through government orders with support of WISH staff members.(7)

Important excerpts of the Telemedicine Guidelines: Telemedicine Practice Guidelines were designed to serve as an aid and tool to Medical Officers to effectively leverage telemedicine to enhance health services and access to all in India. The guidelines clearly illustrate the telemedicine applications along with important elements to be considered before its start and same is shown underneath. (Table-1)

\section{Summary}

In Madhya Pradesh, within 4 days of the establishment of telemedicine unit, more than 13700 home quarantined individuals have been successfully tele-consulted through medical officers across 51 districts and managed as per the protocols; out of these 757 individuals were connected through 104/108 ambulance services and nearly 3671 individuals are connected through district MMU/RRT units for further management. Telemedicine is of paramount importance at this unprecedented situation that humanity is facing. With the recent guidelines of telemedicine issued, it would only be prudent to commence this system and contribute to this global fight against COVID-19.

\section{Way forward}

Telemedicine cannot be the answer to all problems; however, it has crucial significance in addressing a vast range of problems, especially in pandemic situations such as COVID-19.(8) The success of the tele-health project indicates the potential for the use of information and communication technology in the rural areas. Effective leadership, dedication and commitment among the project staff, effective training and development programs for the doctors are the critical success factors. Other states in the country should also move towards establishment of telemedicine units for combating COVID-19.

\section{Authors Contribution}

All authors have contributed equally.

\section{References}

1. WHO report on emergency preparedness responses [Internet]. Pneumonia of unknown cause - China; [updated on 5th Jan 2020 cited on 10th April 2020]. Available from: https://www.who.int/csr/don/05january-2020-pneumonia-of-unkown-causechina/en/

2. COVID-19 Dashboard by the Center for Systems Science and Engineering (CSSE) at Johns Hopkins University (JHU) [Internet]; [updated and cited on 10th April 2020]. Available from: https://coronavirus.jhu.edu/map.html

3. Duffy S, Lee TH. In-person health care as option B. N Engl J Med 2018;378:104-6.

4. Lurie N, Carr BG. The role of telehealth in the medical response to disasters. JAMA Intern Med 2018;178:745-6.

5. Joshi AU, Randolph FT, Chang AM, et al. Impact of emergency department tele intake on left without being seen and throughput metrics. Acad Emerg Med 2020; 27:139-47

6. Telemedicine Practice Guidelines [Internet]. Enabling Registered Medical Practitioners to Provide Healthcare Using Telemedicine; [updated on 22nd March 2020 cited on 10th April 2020]. Available from: https://www.mohfw.gov.in/pdf/Telemedicine.pdf

7. National Health Mission- guidelines and instruction for establishing telemedicine units issued by Government of Madhya Pradesh: State guidelines to 
districts for establishment of telemedicine units

[Issued on 26th March 2020 and 1st April 2020].
8. Kailasam S, Kumar S, Dharanipragada J. Arogyasree: An enhanced grid-based approach to mobile telemedicine. Int J Telemed Appl. 2010;2010:536237.

\section{Tables}

\section{TABLE 1 TELEMEDICINE APPLICATION AND KEY ELEMENTS}

Telemedicine Application

- Mode of communication (Video, Audio, Text)

- Time of information (Concurrent/ real Time, Asynchronous

- Individual involvement (Patient to RMP, Caregiver to RMP, RMP to RMP, Healthcare worker to RMP

- Purpose of consultation (Emergency and nonemergency both.

*RMP-Registered Medical Practitioners
Key Elements

- Establishing 24*7 telemedicine units (8 hourly duty rosters for 3 teams of 1-MO, 1-paramedic staff and 1-data manager each)

- Dedicated phone, mobile/WhatsApp numbers, Email ID, video call facilities etc.

- Providing telemedicine unit contact details to Home Quarantined individuals.

- Providing 24*7 tele-consultation services through trained staff

- Tele-triaging on the basis of symptoms

- Providing management as per the telemedicine guidelines issued by Government of Madhya Pradesh

\section{Figures}

\section{FIGURE 1 SCHEMATIC DIAGRAM-TELEMEDICINE UNIT DATA FLOW}

\section{Data flow for Home quarantined individuals via telemedicine units}

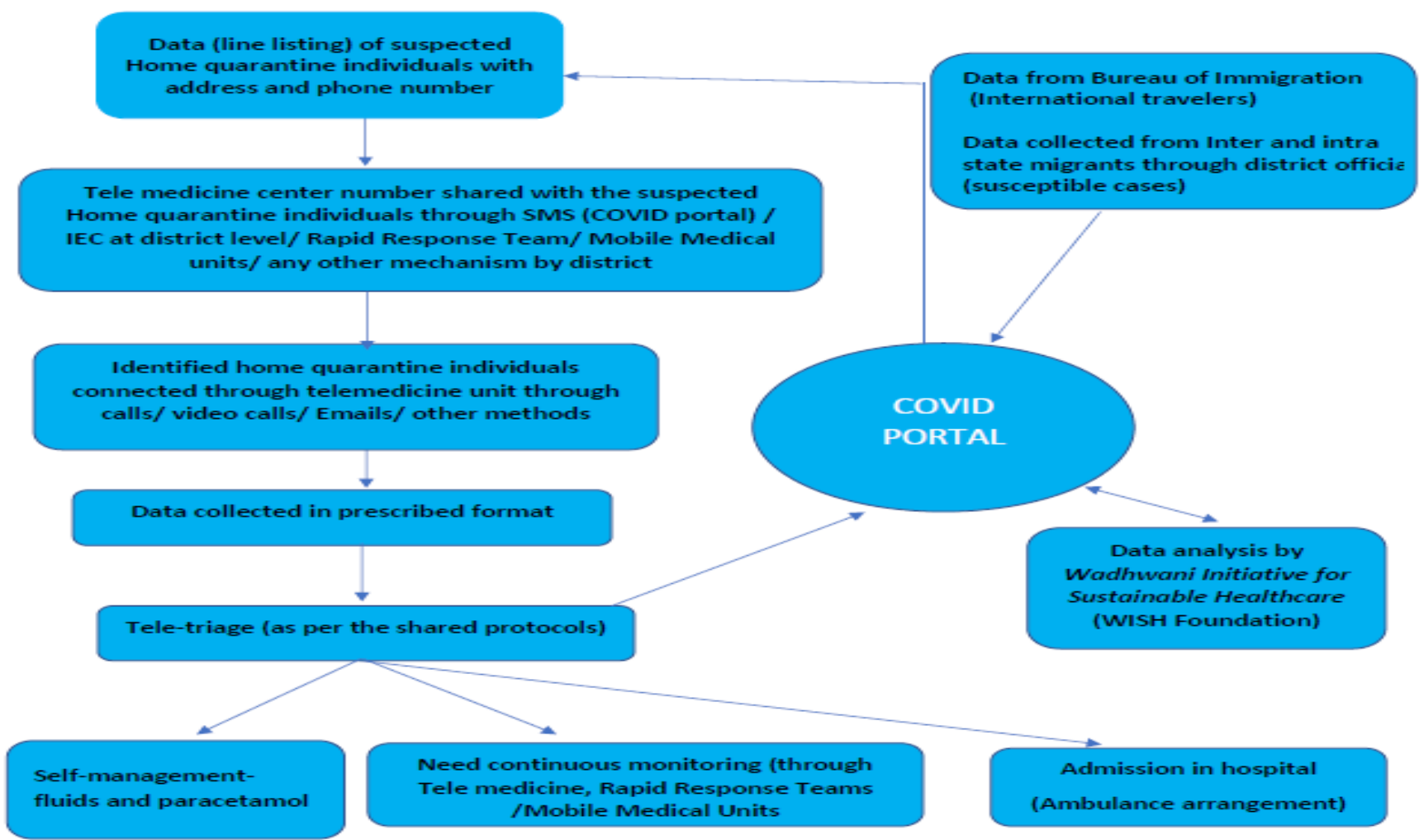




\section{FIGURE 2 SOAR ANALYSIS OF TELEMEDICINE UNITS FOR COVID-19 MANAGEMENT}

\section{SOAR (Strengths-Opportunities-Aspirations-Results) analysis:}

\section{Telemedicine units for COVID-19}

- Prevents spread of COVID-19 infection

- Improved quality of care for Home Quarantined individuals

- Improved access to information, services and care delivery

- Patients- increased convenience, cost and time savings

- Optimum utilization of trained manpower and other resources

- Faster access to the health professional and real time data

- Decreased burden on health facilities so increased quality on regular consultations

- Provision of care not previously deliverable

- Improved access to latest information/guidelines

- Improved professional education

- Reduced health-care costs

- Overall Health system strengthening

- Rapport building and trust on health department
- Rationalized usage within primary, secondary and tertiary care

- Once fully established, this platform can be utilized for other RMNCH+A and NCD services too

- Health system preparedness for any other anticipated/ unanticipated epidemics

- Quality of health information can be strengthened

- Organizational and bureaucratic difficulties can be minimized

- Bending the curve of COVID-19 spread by

- Early diagnosis of suspected cases

- Decongestion at district hospital and medical colleges

- Continuous surveillance of home quarantined citizens

- Ensuring prompt action by RRT/MMU/Ambulance services

- Appropriate health education and counselling to all

- Mental health of all home quarantined persons taken care through appropriate counselling 